\title{
TENSÕES E INTENÇÕES ENTRE PROFESSOR DE GEOGRAFIA E LIVRO DIDÁTICO NA PRÁTICA DOCENTE
}

\author{
Tensions and intentions between geography teacher and textbook in teaching practice
}

\author{
Carina Copatti* \\ Helena Copetti Callai ** \\ * Doutoranda do PPG em Educação nas Ciências - UNIJUI - carina.copatti@gmail.com. \\ **Professora do PPG em Educação nas Ciências - UNIJUI - copetti.callai@gmail.com.
}

\author{
Recebido em 04/08/2018. Aceito para publicação em 20/08/2018.
}

Versão online publicada em 03/08/2018 (http://seer.ufrgs.br/paraonde)

\begin{abstract}
Resumo:
O objetivo desta escrita é propor reflexões em relação às tensões entre professor de Geografia e livro didático na prática de ensino, considerando também as intenções dos profissionais no uso deste recurso. Trazemos como questão central: de que maneira a relação entre o professor de Geografia e o livro didático influencia na prática docente? Como esse recurso interfere no ensino de Geografia? Como metodologia optamos pela pesquisa bibliográfica, construída no âmbito inicial da pesquisa de doutoramento, em que a interação entre livro didático e formação de professores tem centralidade. São diversas as interações possíveis entre professor e livro didático; isso envolve a formação teórico-metodológica, os conhecimentos didáticopedagógicos e as experiências que o professor possui. Isso faz com que ocorram tensões no uso desse recurso ou, ainda, que diferentes possibilidades emerjam nessa interação.
\end{abstract}

Palavras-chave: Professor de Geografia; Livro didático; Ensino e aprendizagem.

\begin{abstract}
:
The purpose of this writing is to propose reflections about the tensions between a geography teacher and textbook in teaching practice, considering also the intentions of the professionals in the use of this feature. We bring as central issue: how the relationship between the geography teacher and textbook influence on teaching practice? As this feature interferes with the teaching of geography? How we chose the bibliographical research methodology, built under the doctoral research, in which the interaction between textbooks and training of teachers has centrality. Are several possible interactions between teacher and textbook; This involves theoretical and methodological training, didactic-pedagogical knowledge and experience that the teacher has. This causes tensions occur in the use of this feature or that different possibilities to emerge in this interaction.
\end{abstract}

Key-words: Geography teacher; Textbook; Teaching and learning.

\section{Introdução}

A tradição escolar tem destacado a utilização de livros didáticos em sala de aula desde o século XIX, e tem o desafio de, no contexto atual, refletir sobre a qualidade desses recursos, para que sejam materiais de qualidade, atualizados e adequados ao contexto atual, amplamente dinâmico e complexo. 
O livro didático, desde o século XIX, tem se configurado como importante recurso que pode ser aliado ao trabalho docente no desenvolvimento das aulas. Especificamente na disciplina de Geografia, pode ser considerado um material complementar importante ao trabalho docente por contribuir a partir de ilustrações, mapas e propostas didáticas interessantes. Porém, em muitas realidades, tem sido frequente sua utilização como único recurso didático, ou substituindo a aula e, assim, o protagonismo do professor.

Tendo a preocupação com o papel que exerce o livro didático na prática docente, pretende-se, no decorrer desta escrita, refletir sobre a relação professor de geografia-livro didático no processo de ensino da Geografia escolar. Para tanto, a questão central considera de que maneira a relação entre o professor de Geografia e o livro didático influencia na prática docente? Como esse recurso interfere no ensino de Geografia?

Para que isso seja possível, através de pesquisa bibliográfica, pretende-se tratar essa relação tão importante e presente no cotidiano da sala de aula. As reflexões propostas são parte da pesquisa desenvolvida em âmbito de doutorado no Programa de Pós-Graduação em Educação nas Ciências da Unijuí, e tem centralidade na relação Livro didático-formação do professor de Geografia.

\section{Desafios da Geografia na contemporaneidade}

A Geografia, no contexto contemporâneo, assume diversos (e complexos) desafios frente às transformações do mundo. Diversos pois além da tradição desta ciência, enquanto disciplina acadêmica, constitui espaço de formação dos profissionais para atuarem em sociedade na leitura e na compreensão dos fenômenos que ocorrem cotidianamente nos mais diversos espaços, seja em escala local, regional, nacional ou global; também, enquanto disciplina escolar, tem a incumbência de formar cidadãos críticos e atuantes frente ao contexto atual de intensas transformações no campo social, político, econômico, nas relações com a natureza.

Estes desafios são complexos, pois, frente às interações impostas numa sociedade na qual as mudanças se configuram rapidamente, as informações circulam e se tornam obsoletas, as relações sociais ganham novas configurações em reduzido espaço de tempo, o que torna a Geografia ainda mais importante, pois assume a tarefa de, através de seu objeto, categorias e conceitos, possibilitar a leitura e a compreensão do mundo. Mas isso só é possível a partir de um conjunto de conhecimentos sistematizados, que dão suporte às leituras na contemporaneidade.

A fim de alicerçar as reflexões propostas, parte-se da necessidade de refletir sobre a constituição da Geografia como ciência, esta que é a base do conhecimento do professor. É a partir destes conhecimentos que desenvolve-se a prática docente e se constituem outros saberes, fundamentais ao processo de ensino e aprendizagem.

Os primeiros conhecimentos considerados "geográficos" foram sistematizados pelos gregos, que buscaram explicar o mundo pela razão. Posteriormente, se expandiu o conhecimento empírico com as grandes navegações, resgatando a geografia grega (CLAVAL, 2015). O século XVIII marca os primeiros avanços na constituição da geografia, tendo se consolidado em suas bases teóricometodológicas no século XIX, o que possibilitou, gradativamente, novos avanços para a compreensão do espaço geográfico. Na Alemanha, pelo trabalho de Alexander Von Humboldt e Carl Ritter, a Geografia alcançou caráter científico, constituindo-se por um caráter estritamente descritivo, positivista e fragmentado. Assim foi possível a definição do campo da Geografia, configurando sua fase clássica até a primeira metade do século XX (CLAVAL, 2015; MORMUL E ROCHA, 2013).

Com os avanços e as transformações sociais, políticas e econômicas do século XX, a Geografia foi sendo conduzida (ou forçada) a transformar-se. Outros pensadores, a partir de concepções distintas, proporam avanços para esta ciência. Diferentes concepções/correntes de pensamento da Geografia surgiram, desenvolvendo outras formas de análise e compreensão do espaço geográfico. Dessa forma, a partir de sua condição inicial descritiva ocorreu na Geografia uma evolução constante e 
maior apuração, complexificação e significação de seu objeto de estudo, atribuindo-lhe um caráter sistêmico, analítico e dinâmico, sugerindo uma dialética, sobretudo na educação geográfica escolar (ANDREIS, 2009).

No que tange à Geografia como disciplina escolar, inicialmente assumia traços estritamente positivistas, passando, posteriormente, a ser influenciada pelas concepções críticas, contribuindo para a interpretação da realidade vivenciada pelas diferentes sociedades em interação entre seus membros e com outros grupos, modificando o espaço geográfico e se modificando, continuamente.

"A história da Geografia como disciplina tem início no século passado, quando foi introduzida nas escolas com o objetivo de contribuir para a formação dos cidadãos a partir da difusão da ideologia do nacionalismo patriótico" (CAVALCANTI, 2010, p. 18). Mais tarde, conforme a autora, sua função ideológica reaparece, quando foi caracterizada pela transmissão de dados e informações gerais sobre os territórios do mundo e de países em particular. Contudo, a necessidade de reformulações na ciência geográfica fez refletir também no ambiente escolar tais necessidades, defendendo a implementação de uma geografia de perspectiva crítica em substituição à geografia tradicional.

Na atualidade, há que se pensar uma Geografia que auxilie a compreensão do mundo e de suas transformações. A Geografia, nesse sentido, tem assumido novas configurações, propondo-se a ir além das concepções fragmentárias existentes até então, estabelecendo associações entre as dimensões natural e humana, buscando, ainda, superar a dualidade entre teoria e prática e, pelas bases científicas dessa área do conhecimento, tecer a estrutura que alicerça estas dimensões e que conduz o que ensinar, o porquê ensinar e como ensinar geografia.

No que tange à Geografia escolar, esta passa atualmente por um processo de reflexões/questionamentos, tanto entre autores/pesquisadores, quanto entre um grande número de professores que atuam na educação básica, comprometidos com a qualidade da abordagem dessa ciência na escola, contribuindo à formação dos cidadãos.

Diante das necessidades atuais e levando em conta o papel da ciência geográfica para a compreensão do mundo, há como centralidade, em muitas pesquisas, a qualidade na formação dos professores para atuar no processo de ensino e aprendizagem da Geografia escolar. Essa questão é importante pois, para alcançar maior qualidade e maior êxito no processo educativo, os professores precisam de uma formação baseada no conhecimento estruturado a partir da ciência. Se o professor não conhece em profundidade o que essa ciência construiu, como assegurará a construção do conhecimento no aluno e sua aprendizagem?

Nesse sentido, se houver inconsistência na formação inicial dos professores, possivelmente pode ocorrer um movimento em que o profissional tende a ancorar-se no Livro Didático, que pode se tornar a força norteadora do pensamento do professor. Assim, o papel que o Livro Didático assume em sala de aula, por vezes é de centralidade, como elemento que define a prática do professor. Surgem, então diferentes tensões entre o Livro Didático e o professor de Geografia que precisam ser considerados, pois são constituintes do cotidiano da sala de aula e influenciam diretamente no modo como esse processo se efetiva cotidianamente e ao longo do tempo.

A mediação realizada pelo professor é extremamente importante na formação de milhares de crianças e jovens do país e não pode ser substituída pelo Livro Didático, por melhor que este seja. No contexto da Geografia, espera-se que o professor assuma a centralidade na educação em sala de aula, e o Livro didático seja utilizado como um dos suportes que pode contribuir para o desenvolvimento da aula e para a aprendizagem dos alunos.

No contexto escolar contemporâneo, a ciência geográfica precisa dar conta de um complexo emaranhado de conhecimentos, mudanças, rupturas e novas construções, as quais demandam profissionais capacitados e engajados no efetivo processo de ensino e aprendizagem. Conforme corrobora Straforini, "para alguns autores o ensino de Geografia é fundamental para que as novas gerações possam acompanhar e compreender as transformações do mundo, dando à disciplina geográfica um status que antes não possuía" (STRAFORINI, 2004, p. 51), alcançando um patamar importante visto que compreende as interpretações das relações que se efetivam entre os seres 
humanos e destes com a natureza.

A formação do professor de Geografia, que acontece de modo constante e em diferentes momentos, pela dimensão teórico-metodológica, didático-pedagógica e a partir da construção de variados conhecimentos ou "saberes" que emergem de aspectos pessoais e da experiência docente, desafia os profissionais a atuarem socialmente e mediar a formação cidadã, para que compreendam e se posicionem frente às dinâmicas do mundo. Para que isso seja possível, é importante considerar a formação deste profissional desenvolvendo a dimensão humana, ética e a sensibilidade para trabalhar com o aluno. Nesse processo tende a desenvolver-se como cidadão crítico e reflexivo no processo de formação humana e desenvolver essas potencialidades na formação destes estudantes.

Cidadão no sentido de posicionar-se em sociedade, sabendo interagir, participar, exercendo seus direitos e deveres de maneira que ajude a construir um processo de convivência coerente. Crítico para entender a realidade e atuar como agente questionador, conhecedor dos processos sociais que $o$ envolvem. E reflexivo no sentido de saber compreender as dinâmicas que ocorrem na sociedade, as possibilidades que emergem das relações sociais e na convivência em sala de aula.

Para que isso seja possível, a atuação do professor a partir de conhecimentos e concepções que lhe possibilitem assumir a autoria no trabalho docente tem valor essencial, o que tende a se efetivar no decorrer do seu trabalho, ao aliar teoria e prática de modo articulado. Isso pode ser construído a partir de um planejamento que envolva os elementos essenciais para a compreensão do espaço geográfico. Nesse processo, o pensamento geográfico, que é base da Geografia como ciência, constitui-se como fundamental no ensino da Geografia, a partir de categorias, conceitos e princípios próprios, que compõe a estrutura dessa ciência, cujas bases possibilitam aos professores contribuir para a educação geográfica.

A partir disso, o professor passa a assumir o controle da aula, dos processos didáticos e pedagógicos no ensinar, na mediação da aprendizagem do aluno, considerando a sua realidade, adequando os conteúdos a partir de conceitos e do desenvolvimento cognitivo destes, visando uma aprendizagem significativa. Nesse movimento, o livro didático é utilizado como suporte, e o professor, tende a criar diferentes intenções de utilização, de acordo com suas necessidades.

\section{Tensões entre professor de Geografia e Livro Didático e as intenções de uso do Livro Didático na prática docente}

Diversas pesquisas vêm sendo realizadas ao longo das últimas décadas, tanto preocupando-se com o conteúdo dos livros didáticos, seu enfoque teórico-metodológico, quanto em relação à utilização desse material pelos professores, o que se faz necessário para a qualificação cada vez maior do material e do seu uso em sala de aula.

Verifica-se que, em muitas realidades no país, o livro didático é o único recurso disponível nas escolas e, na atualidade, mesmo diante das transformações provenientes dos avanços tecnológicos, que permitem que se utilizem recursos e metodologias diversas, continua sendo, "[...] o recurso mais presente em sala de aula, quando não é a própria aula, a voz principal no ensino" (SCHÄFFER, 1999, p. 141).

No Brasil, apesar da utilização de livros didáticos no sistema público de ensino, e de existirem orientações e diretrizes curriculares que orientem o processo educativo, é possível ao professor, em sala de aula, ter certa autonomia na condução do que, quando e como abordar determinados assuntos. No entanto, tendo em vista que, em muitos momentos, o livro didático é utilizado como "manual" que conduz o professor, como receita pronta a ser seguida, nota-se certa dificuldade em estabelecer essa autonomia. Diante disso, questiona-se: que papel assume o livro didático nas aulas de Geografia? Que significados têm para o professor?

Compreende-se que a maneira como o professor se relaciona com o livro didático pode 
desencadear diferentes situações, dentre elas várias possibilidades de uso deste recurso, de acordo com as intenções do docente, ou inúmeras tensões que precisam ser constantemente analisadas.

Quando falamos dos livros didáticos de Geografia surge o questionamento de como esse material é utilizado pelos professores em sala de aula, isso porque o livro didático configura-se como um material carregado de significados culturais, políticos e sociais que, de modo mais intenso ou menos intenso, influenciam no trabalho do professor. Talvez essa seja uma tensão existente entre o livro didático e o professor em sala de aula, visto que o livro didático se constitui como um recurso carregado de significados de uma determinada cultura. Uma das funções do livro didático é ideológica, capaz de forjar situações consideradas "adequadas" ou "inadequadas", formas de percepção de mundo e até mesmo assumindo um importante papel político, na medida em que perpetua visões de mundo hegemônicas em detrimento de outras culturas e formas de viver e perceber a relação homem-sociedade-natureza e suas implicações e transformações no decorrer do tempo (CHOPPIN, 2004, p. 553).

Ainda, o livro didático, muitas vezes, é tido como "insubstituível e se caracteriza como o instrumento adequado para transformar a mensagem científica em mensagem educativa, pois é o único recurso capaz de transmitir sistematicamente um corpo de conhecimento" (STEFANELLO, 2011, p. 84). No entanto, questiona-se essa afirmação pois o livro didático não se constitui de um recorte "transposto" da linguagem científico-acadêmica para a linguagem escolar. 0 livro didático apresenta um conjunto de conteúdos sistematizados a partir da ciência geográfica, utilizando-se de um formato linguístico, pedagógico, adequado ao nível escolar, contendo conteúdos selecionados a partir da visão dos autores que o escreveram. Nesse sentido,

Nenhum currículo é "naturalmente existente". Os currículos são sempre construídos, os temas são pautados, e o são de acordo com os interesses que existem assentados em correntes teóricas diversas e num jogo de força (acadêmico e político) que se apresentam ao professor como aquilo que deva ser ensinado (CALLAI, 2016, p. 294).

Nesse processo, o professor precisa conhecer o livro didático que utilizará em sala de aula para que possa reconhecer em que situações pode dele se utilizar, que conteúdos selecionar, que abordagem fazer a partir do conteúdo disponibilizado. Esse material precisa ser constantemente analisado pelo professor, repensadas as suas propostas, no sentido de adequar-se ao contexto em que atua, para que, efetivamente contribua no processo de ensino e aprendizagem; isso porque o livro didático é apenas um dos suportes de ensino disponibilizado aos professores para facilitar a construção de conhecimentos. Sendo assim, não pode ser utilizado como um "manual" a ser seguido rigorosamente.

Verifica-se que as tensões nessa relação são muitas, dentre elas o desafio de adequar a linguagem e os conteúdos do livro didático para um grande contingente de crianças e jovens estudantes de todas as regiões do país. Num território tão extenso e diverso, em termos de etnias, culturas, contextos de vida, etc, é evidente que utilizar um único livro didático em todo o território constitui-se de uma tarefa difícil e complexa. Questiona-se se "é possível um currículo único em todo o Brasil? Daí decorre a outra pergunta: é possível um livro único que oriente todos os alunos de todo o território brasileiro considerando a nossa diversidade geográfica numa perspectiva global, mas também em escala local?" (CALLAI, 2016, p. 295).

Diante disso, como estabelecer os conteúdos de acordo com o que é mais adequado para determinado lugar/determinada região? De que modo abordá-los em sala de aula num contexto diverso? No centro de uma grande metrópole, no cotidiano dos povos ribeirinhos da Amazônia ou no interior dos pequenos municípios dos estados do nordeste ou do sul? De que modo adequar este material a fim de que o estudante compreenda a linguagem nele utilizada e compreenda os conteúdos essenciais à geografia?

Na relação com o LD, o professor, se bem constituído em suas bases teórico-metodológicas, tem nelas o suporte necessário para fazer escolhas e adequações, tendo em vista que é o conhecimento de base da ciência geográfica, de seus conceitos e categorias, que o profissional tem a possibilidade de 
refletir, fazer escolhas, repensar, readequar este material ao contexto em que atua, à realidade local, sua linguagem, suas abordagens, às vivências dos estudantes, buscando estabelecer relações entre diferentes escalas.

Nesse processo, é preciso considerar que conhecimentos são base para a educação geográfica? Que elementos permitem desenvolver a Geografia como parte do cotidiano e não como algo distante e complexo?

Ao aprender Geografia, enquanto professores, dotamo-nos de conhecimentos acerca da constituição histórica e científica dessa ciência, e nesse contato, pouco a pouco nos imbuímos da tarefa de contribuir para outras aprendizagens no ambiente escolar e também fora dele. Para tanto, é necessário considerar a constituição da ciência geográfica e suas transformações, as dinâmicas que perpassam a Geografia no contexto contemporâneo, imbricadas no processo de ensino e aprendizagem, que são tarefas do professor de Geografia na educação básica.

Nesse sentido, é fundamental que esteja claro que Geografia é ensinada na escola e nos cursos de formação docente, pois "sem esta clareza, o professor reproduz conteúdos constantes de material didático: livros, textos que recontam as suas aulas (repete a cada ano as mesmas coisas) e faz um trabalho mais burocrático que, na maior parte das vezes é pedagogicamente precário" (CALLAI, 2010, p. 17). Muitas vezes isso se reverte em dificuldades de definir que parâmetros utiliza para a prática que realiza, que elementos definem as escolhas que faz, tanto em relação aos procedimentos didático-pedagógicos, quanto em relação à escolha do LD ou de que forma utilizá-lo nas aulas.

Assim, dentre as intenções que se apresentam na relação com o LD, uma condição diz respeito ao modo como o professor se apropria dos conhecimentos construídos pela ciência geográfica, constitui seu pensar sobre a Geografia, o seu pensamento geográfico, e dele se apropria para o cotidiano da docência.

Um possível caminho, segundo Souza (2011) para o desenvolvimento do pensamento geográfico decorre da aprendizagem de conceitos que estruturam o pensamento espacial; são eles: paisagem, lugar, região, espaço e território (CORRÊA, 2000). Suertegaray acrescenta os conceitos de ambiente e rede, operacionais "na medida em que permitem focar o espaço geográfico sob uma perspectiva" (SUERTEGARAY, 2005, p. 49). Tais conceitos e as diferentes correntes de pensamento geográfico contribuem à construção do pensar do professor e compõem as bases de conhecimento geográfico, contribuindo para que o profissional desenvolva seu trabalho fazendo escolhas e adaptações do livro didático.

É preciso que se leve em conta que a aprendizagem é um processo do aluno, sendo as ações propostas pelo professor; a utilização do livro didático precisa partir das necessidades de construção do conhecimento do aluno. Todo esse processo demanda conhecimento teórico-metodológico e pedagógico por parte do professor, além de abertura à mudança a fim de compreender as dinâmicas que envolvem a Geografia. Envolve ainda a inserção do professor no ambiente em que atua, no sentido de dar novos significados à educação geográfica que propõe em sala de aula. É preciso refletir sobre o modo como formar os alunos para o mundo da vida, auxiliando-os na formação para a cidadania, para a reflexão, para a inquietude, para participar ativamente das escolhas que perpassam as vivências em sociedade.

O livro didático configura-se como um material carregado de significados culturais, políticos e sociais que, de certo modo, quando não adaptados à realidade da escola e do aluno, se confrontam com sua realidade étnico-cultural, negam-na ou camuflam sua abordagem. Nesse sentido, no processo de ensino e aprendizagem de Geografia, a visão limitadora do livro didático pode contribuir para perpetuar certas dicotomias e padronizações até então bastante frequentes, que, de certa forma, tendem a construir identidades, camuflar situações e impor percepções de mundo equivocadas. Isso gera tensões entre a linguagem/estrutura desse recurso didático, a realidade dos estudantes e as necessidades do ensino que precisam ser supridas.

0 papel do professor tem grande peso no processo educativo visto que pode instigar diferentes leituras do espaço, das relações entre os sujeitos e suas culturas. Para tanto, o professor pode 
desenvolver novas interpretações e compreensões do livro didático junto ao estudante, trazendo ao debate situações cotidianas vivenciadas por ele, indo além do conteúdo disponibilizado neste material e da ideia de simplesmente transmir, em sala de aula, informações e conhecimentos.

Neste contexto se destaca a necessidade de formação permanente em busca da autonomia intelectual para tomar decisões, contribuindo para que o professor seja capaz de fazer escolhas ancoradas no conhecimento teórico-metodológico. Se faz necessário, nesse sentido, utilizar-se de outros elementos na construção do conhecimento que possam assegurar a qualidade do processo por meio de diversas fontes, assumindo o livro didático como um parceiro no processo, um elemento de pesquisa ao estudante, como um material que pode ser utilizado nos estudos escolares e em casa. "Através do LD muitas famílias têm o único livro que pode ser manuseado que pode ser lido, que pode ser considerado uma fonte de informação" (CALLAI, 2016, p. 295). Desse modo, não podemos desmerecer sua importância, mas sim, ter a consciência de que é o professor quem define os procedimentos que precisam ser tomados em sala de aula.

A autonomia do professor que se baseia no conhecimento teórico-metodológico e outros conhecimentos e saberes inerentes à profissão professor, contribui à construção do conhecimento indo além do livro didático como um manual de instruções ou receituário. Estando o professor consciente da dinâmica que envolve o ensino e a aprendizagem escolar, pautado na estrutura da ciência que ensina, poderá desenvolver a autonomia de pensamento ao se utilizar do livro ou de qualquer outro recurso em sala de aula. Sendo assim, estabelece suas intenções em relação ao livro didático, considerando os mais diversos aspectos que interferem na educação escolar e na realidade em que atua.

O livro didático pode ser utilizado em diversos momentos, a partir de diferentes propostas que o professor considere mais viáveis para o desenvolvimento das aulas de Geografia. A partir do livro didático poderá usufruir de suas diversas seções complementares, de mapas, gráficos, atividades sugeridas, as quais podem ser adaptadas à realidade em que atua, além de se utilizar de leituras complementares, caso sejam adequadas ao contexto, ao conteúdo, enfim, à dinâmica da aula. Nesse sentido, a autonomia docente em relação ao livro didático parte do pressuposto de que o professor está consciente dos diversos elementos que estruturam o ensino escolar e que, no ensino de geografia precisam ser considerados.

Assim, não torna esse material o "guia" no desenvolvimento da aula, não o torna fonte única de informações e procedimentos didático-pedagógicos, permitindo-se explorar outras fontes, outras metodologias, que contribuam para potencializar a aprendizagem e tornar o processo educativo mais significativo aos estudantes.

\section{Considerações Finais}

O Livro didático é considerado, por muitos autores, como um importante recurso didático na educação básica e, em muitas realidades, é o único material que chega até os alunos. Este recurso influencia no ensino de Geografia e gera algumas tensões no trabalho do professor em sala de aula, tanto em relação ao uso de seus diferentes conteúdos quanto à linguagem e outros elementos que são característicos de cada autor que o escreve, seguindo determinadas tendências teóricometodológicas.

Desta forma, as interações entre professor e livro didático se efetivam de modo diverso, fazendo com que ocorram tensões no uso desse recurso entre as suas propostas, as necessidades do contexto escolar e a realidade dos estudantes.

Para conhecer as tensões existentes na relação professor de Geografia-livro didático se torna importante um olhar ao campo empírico, para além do que a literatura nos disponibiliza. Conhecer o livro didático, pesquisar seu uso em sala de aula, compreender através do olhar do professor os 
elementos que emergem da interação com este material didático possibilita avançar para além do conhecimento teórico sobre o livro didático. Este passa a ser um dos aspectos prioritários para avançar na compreensão da questão, visto que, é no contexto da prática educativa que estas tensões se evidenciam e podem influenciar no processo de ensino e aprendizagem que se efetiva em sala de aula, na interação entre o professor de Geografia e os estudantes.

Sendo este um dos únicos materiais (ou o único!) que chega à casa de cada estudante e que serve de fonte de leitura e informação, os professores, podem utilizá-lo a partir de elementos que sejam realmente importantes para a aprendizagem. Nesse sentido, a partir de intenções diversas, o professor pode realizar complementações, adequações de linguagem, utilização de atividades, textos, seções complementares, de acordo com sua interpretação em relação ao livro didático.

Essa possibilidade permite ao professor assumir uma postura crítica que se constrói a partir do conhecimento em relação à ciência geográfica, de categorias, conceitos e outros elementos que lhe dão sustentação para a prática de ensino, sem ancorar-se no livro didático como um manual a ser rigorosamente seguido. Esse processo, envolve, portanto, a autonomia docente na condução do processo educativo, tornando possível que, na interação com os livros didáticos, estabeleça critérios e caminhos no intuito de potencializar a aprendizagem e a construção da educação geográfica.

\section{Referências}

ANDREIS, Adriana M. Da informação ao conhecimento: cotidiano, lugar e paisagem na significação das aprendizagens geográficos na educação básica. (Dissertação de Mestrado). UNIJUI, 2009.

CALLAI, Helena C. O livro didático permite e oportuniza a democratização do conhecimento? In: SPOSITO, Eliseu [et. al.]. A diversidade da geografia brasileira: escalas e dimensões da análise e da ação. 1. Ed. Rio de Janeiro: Consequência Editora, 2016.

CALLAI, Helena C. A Geografia ensinada: os desafios de uma educação geográfica. In: MORAIS, Eliana M. Barbosa de. MORAES, Loçandra B. de. (Orgs.) Formação de professores: conteúdos e metodologias no ensino de Geografia. Goiânia: NEPEG, 2010.

CAVALCANTI, Lana de S. Geografia, escola e construção de conhecimentos. 16 Ed. Campinas, SP: Papirus, 2010.

CHOPPIN, Alan. História dos livros e das edições didáticas: sobre o estado da arte. Educação e Pesquisa. Revista da Faculdade de Educação da USP. São Paulo, v. 30, n. 3, p. 549-566, set./dez. 2004.

SCHÄFFER, Neiva Otero. $O$ livro didático e o desempenho pedagógico: anotações de apoio à escolha do livro texto. In: CASTROGIOVANNI, Antônio C. [et. al.]. Geografia em sala de aula: práticas e reflexões. 3. Ed. Editora da Universidade/UFRGS/Associação dos Geógrafos Brasileiros. Seção Porto Alegre, 2001.

STEFANELLO, Ana Clarissa. Didática e avaliação da aprendizagem no ensino de Geografia. 2. Ed. IBPEX Editora, 2011.

STRAFORINI, Rafael. Ensinar geografia: 0 desafio da totalidade - mundo nas séries iniciais. São Paulo: Annablume, 2004.

SUERTEGARAY, Dirce M. Notas sobre epistemologia da geografia. Cadernos Geográficos. Universidade Federal de Santa Catarina. Centro de Filosofia e Ciências Humanas. Departamento de Geociências. - n. 12. Florianópolis: Imprensa Universitária, 2005. 